\title{
EFEITOS DE ÉPOCAS DE CAPINAS E DA ADUBAÇÃO NITROGENADA EM COBERTURA SOBRE OS COMPONENTES DE PRODUÇÃO DO FEIJOEIRO. II - CULTIVO DA "SECA" 1
}

\author{
JOSÉ M. V. PAES ${ }^{2}$, ANTÔNIO A. CARDOSO ${ }^{3}$, ANTÔNIO A. DA SILVA ${ }^{4}$ CÉSIO H. DE BRITO
}

\section{RESUMO}

O objetivo deste trabalho foi avaliar os efeitos da adubação nitrogenada em cobertura após a capina, realizada em diferentes épocas, sobre os componentes de produção de três cultivares de feijão (Phaseolus vulgaris L.), no cultivo da "seca". O número de vagens por hectare (NVHA) foi o componente primário de produção mais prejudicado pela competição de plantas daninhas durante todo o ciclo de vida do 'Ouro' e do 'Ouro Negro'. Em todos os experimentos, os atrasos na capina proporcionaram aumento da cobertura real de plantas daninhas, o que causou diminuição da produtividade de grãos (PG) e do NVHA na presença de nitrogênio em cobertura. Nos três cultivares, o nitrogênio aplicado em cobertura promoveu aumentos de PG, NVHA e do peso de 100 grãos (P100G) e promoveu, também, aumento do número grãos por vagem no 'Novo Jalo'. O nitrogênio aplicado em cobertura imediatamente após a capina, realizada com atraso de dez dias, em relação ao período total de prevenção de interferência, que é de 30 dias para a cultura do feijão, não foi capaz de proporcionar recuperação total da capacidade produtiva dos feijoeiros.

Palavras chave: Phaseolus vulgaris, planta daninha, nitrogênio.

\section{ABSTRACT \\ Effects of weeding and side-dressing of nitrogen fertilizer on different bean development stages. II - "Dry" crop season}

The purpose of this work was to evaluate the effects of side-dressing of nitrogen fertilizer after weeding in different periods on bean culture (Phaseolus vulgaris L.) of three types of growth habits, during the "dry" crop season. Number of pods per hectare (NPH) was the primary production component which was most harmed by weed competition throughout the life cycle of 'Ouro' and 'Ouro Negro'. In all the experiments the different weeding delays increased actual weed side-dressing which decreased GP and NPH in the presence of side-dressing application of nitrogen. In the three cultivars, side-dressing application of nitrogen fertilizer increase GP, $\mathrm{NPH}$ and 100 grain weight $(100 \mathrm{GW})$ as well as the number of grains per pod (NGP) in 'Novo Jalo'. When side-dressing application of nitrogen fertilizer was done immediately after weeding delayed $10 \mathrm{~d}$, in relation to the total period of interference prevention ( $30 \mathrm{~d}$ for bean culture), it was not capable of provinding total recovery of the beans productive capacity.

Key words: Phaseolus vulgaris, weed, nitrogen.

\footnotetext{
${ }^{1}$ Recebido para publicação em 14/10/97e na forma revisada em 13/01/99.

${ }^{2}$ Eng. Agr., DS, Pesquisador EPAMIG/CTTP. C.P. 351, CEP: 38001 -970, Uberaba/MG.

${ }^{3}$ Eng. Agr., DS, Professor Titular do Departamento de Fitotecnia/UFV. CEP: 36571-000, Viçosa/MG.

${ }^{4}$ Eng. Agr., DS, Professor Adjunto do Departamento de Fitotecnia/UFV. CEP: 36571-000, Viçosa/MG.

${ }^{5}$ Eng. Agr., DS, Professor Visitante do Departamento de Agronomia/UFU. CEP: 38406-902, Uberlândia/MG.
} 


\section{INTRODUÇÃO}

O cultivo do feijão da "seca", cuja semeadura normalmente é realizada em fevereiro ou março, é considerado de risco, pois a possibilidade de escassez de chuva no período de floração e de enchimento de vagens é alta, o que pode causar perdas parciais ou totais na produção.

Em 1994, no Brasil, o cultivo da "seca" foi responsável por $41 \%$ da área plantada e $42 \%$ da produção, apresentando baixa produtividade de grãos: $614 \mathrm{~kg} / \mathrm{ha}$ (Instituto Brasileiro de Geografia e Estatística, 1995). O baixo rendimento do feijoeiro pode ser explicado porque as lavouras são conduzidas, na maioria das vezes, por pequenos agricultores descapitalizados, portanto, sem recursos para utilização de insumos. Ademais, normalmente o cultivo é feito em solos empobrecidos, empregando-se baixo nível tecnológico e a grande maioria dos produtores faz o cultivo em consórcio, após a maturação fisiológica do milho ou quando as plantas começam a secar.

Calvache et al. (1995) verificaram que, para o feijão, o bom manejo da irrigação foi condição necessária para a resposta à utilização de $80 \mathrm{~kg} / \mathrm{ha}$ de $\mathrm{N}$, dose que proporcionou produtividade $3015 \mathrm{~kg} / \mathrm{ha}$. Observaram, ainda, que não houve resposta à aplicação desse nutriente, quando fizeram restrição de água no período de florescimento.

Diversos são os fatores que podem influenciar a resposta da cultura do feijão ao nitrogênio, sendo um deles a presença de plantas daninhas. Portanto, elas deverão ser controladas antes de iniciarem a interferência sobre a cultura. Normalmente, existe um período a partir da semeadura, ou da emergência, em que a cultura pode conviver pacificamente com a comunidade infestante (sem interferência), definido por Pitelli (1985) de período anterior à interferência. Teoricamente, o final desse período seria a época ideal para o primeiro controle da vegetação infestante, para que, na fase crítica (período crítico de prevenção da interferência), a cultura esteja livre da interferência das plantas daninhas. $\mathrm{Na}$ prática, esse deve ser o período em que as capinas ou o poder residual do herbicida devem cobrir.

Independente do produtor usar o manejo correto, quando se atrasa o início da capina ocorrerá competição entre a cultura e as plantas daninhas pelos fatores de produção, havendo redução da produtividade de grãos de feijão (Nieto et al., 1968; Vieira, 1991).

Diante dessa realidade, este trabalho objetivou avaliar os efeitos da adubação nitrogenada em cobertura após a capina, sobre os componentes de produção de três cultivares de feijão (Phaseolus vulgaris L.), no cultivo da "seca".

\section{MATERIAL E MÉTODOS}

Foram instalados três experimentos, na segunda quinzena de março de 1994, e três, na segunda quinzena de março de 1995, utilizandose os cultivares Novo Jalo (tipo I - hábito de crescimento determinado), Ouro (tipo II - hábito de crescimento indeterminado arbustivo, com ramificação ereta e fechada), e Ouro Negro (tipo III - hábito de crescimento undeterminado prostado, com ramificação aberta), em solo Podzólico Vermelho-Amarelo Câmbico, fase terraço, no município de Coimbra-MG. Cada cultivar constituiu um experimento. Na camada de 0-20 $\mathrm{cm}$ de profundidade, esse solo apresentou as seguintes características químicas: $\mathrm{pH}=6,1$, $\mathrm{P}=14 \mathrm{mg} / \mathrm{dm}^{3}, \mathrm{~K}=30 \mathrm{mg} / \mathrm{dm}^{3}, \quad \mathrm{Ca}=2,2 \mathrm{cmol}_{\mathrm{c}} / \mathrm{dm}^{3}$, $\mathrm{Mg}=0,5 \mathrm{cmol}_{\mathrm{c}} / \mathrm{dm}^{3}, \quad \mathrm{Al}=0,1 \mathrm{cmol}_{\mathrm{c}} / \mathrm{dm}^{3} ; \quad$ e texturais: areia $=25 \%$, silte $=12 \%$ e argila $=63 \%$, sendo o solo classificado como muito argiloso.

Os tratamentos foram dispostos em blocos casualizados em esquema fatorial $(6 \mathrm{x}$ $2)+2$, correspondendo a seis épocas de capina: etapas de desenvolvimento $\mathrm{V}_{3}, \mathrm{~V}_{3}+5, \mathrm{~V}_{3}+10, \mathrm{~V}_{3}$ $+15, \mathrm{~V}_{3}+20 \mathrm{e} \mathrm{V}_{3}+25$ dias, duas doses de nitrogênio em cobertura: 0 e $30 \mathrm{~kg} / \mathrm{ha}$ e, dois tratamentos adicionais: testemunha com capina 
(TCC) e testemunha sem capina (TSC), com quatro repetições. A dose de nitrogênio empregada foi de $30 \mathrm{~kg} / \mathrm{ha}$, tendo como fonte o sulfato de amônio, e a adubação no sulco de plantio (650 kg/ha de 4-14-8) foram feitas com base nos resultados da análise química do solo, conforme recomendações da Comissão de Fertilidade do Solo do Estado de Minas Gerais (1989). O nitrogênio foi distribuído em cobertura imediatamente após cada época de capina e, nos tratamentos adicionais no estádio de desenvolvimento $\mathrm{V}_{3}$. Executou-se uma única capina por ocasião de cada etapa de desenvolvimento do feijoeiro. A TCC foi mantida livre das plantas daninhas até o estádio de desenvolvimento $\mathrm{V}_{3}+25$ dias, por meio de três capinas, realizadas aos 15,25 e 40 dias após a emergência das plântulas de feijão (estádio $V_{1}$ ), que foi observada em torno de seis dias após a semeadura. A primeira época de capina teve como referência o estádio de desenvolvimento $\mathrm{V}_{3}$ dos cultivares de feijão (15 dias após emergência), quando a primeira folha trifoliolada de $50 \%$ das plantas estava totalmente expandida.

As plantas daninhas presentes na área do experimento foram: losna-brava (Artemisia verlotorum), botão-de-ouro (Galinsoga parviflora), picão-preto (Bidens pilosa), corda-deviola (Ipomoea grandifolia), trevo (Oxalis oxyptera), tiririca (Cyperus rotundus), gramaseda (Cynodon dactylon) e capim-marmelada (Brachiaria plantaginea). Antes de cada capina, foi feito o levantamento da infest ação de plantas daninhas, avalia ndo -se, visualmente, a percentagem de cobertura real do solo pela comunidade infestante e a percentagem de cobertura real do solo pelas plantas daninhas, por espécie botânica, presentes em cada parcela experimental. As parcelas foram dimensionadas com quatro linhas de 7,5 $\mathrm{m}$ de comprimento, espaçadas de $0,5 \mathrm{~m} \mathrm{e}$ com aproximadamente 15 sementes por metro. A área útil da parcela compreendeu os $4 \mathrm{~m}^{2}$ centrais. Em nenhum momento foi feito o uso de irrigação.

As colheitas foram realizadas quando pelo menos $90 \%$ das vagens estavam secas, conforme orienta Vieira (1991). Nos dois anos, esse ponto de colheita foi observado em torno de 100 dias após o plantio. Nessa ocasião, foram avaliados o estande final por metro (EFM), a produtividade de grãos $(\mathrm{PG}), \mathrm{em} \mathrm{kg} / \mathrm{ha}$, o número de vagens por hectare (NVHA), o número de grãos por vagem (NGV) e o peso de 100 grãos (P100G), em g. O estande inicial por metro (EIM) foi avaliado após completa emergência das plântulas de feijão.

Após a colheita do feijão, fez-se, por amostragem, a coleta das plantas daninhas remanescentes, utilizando-se um quadrado de ferro $\left(0,25 \mathrm{~m}^{2}\right)$, que foi lançado ao acaso, por duas vezes, em cada parcela experimental. Para determinação da massa da matéria seca, as plantas daninhas foram separadas em monocotiledôneas e dicotiledôneas e colocadas em estufa de circulação de ar forçado a $72^{\circ} \mathrm{C}$, por 72 horas.

Inicialmente, foram realizadas as análises de variância de todas as características avaliadas em cada ano de plantio, isoladamente. Posteriormente, efetuou-se a análise de variância conjunta das características, em que os quadrados médios residuais não ultrapassaram uma relação aproximada de 7:1, conforme recomendam Banzatto \& Kronka (1989). Na análise de variância conjunta, foram considerados os efeitos de blocos e anos aleatórios e o efeito de tratamentos fixo. Esses efeitos foram testados de acordo com o que preconizam Cruz \& Regazzi (1994).

\section{RESULTADOS E DISCUSSÃO}

Verificou-se redução significativa da $\mathrm{PG}$ da TSC, em relação à TCC, no 'Novo Jalo', 'Ouro' e 'Ouro Negro' (Tabela 1). A competição de plantas daninhas reduziu a produtividade desses cultivares em 28\%, 36\% e 37\%, respectivamente. Esses resultados estão de acordo com Nieto et al. (1968) e Vieira (1970), que verificaram redução na produtividade de grãos de 
TABELA 1. Valores médios da produtividade de grãos (PG), em kg/ha, do número de vagens por hectare (NVHA), do número de grãos por vagem (NGV) e do peso de 100 grãos (P100G), em g, do 'Novo Jalo', 'Ouro 'e 'Ouro Negro', em cada tratamento, no cultivo da "seca".

\begin{tabular}{|c|c|c|c|c|c|c|c|c|c|c|c|c|}
\hline \multirow[t]{2}{*}{ Tratamentos } & \multicolumn{4}{|c|}{ 'Novo Jalo' } & \multicolumn{4}{|c|}{ 'Ouro' } & \multicolumn{4}{|c|}{ 'Ouro Negro' } \\
\hline & $\mathrm{PG}$ & NVHA $\times 10^{3}$ & NGV & P100G & $\mathrm{PG}$ & NVHA $x 10^{3}$ & NGV & P100G & $\mathrm{PG}$ & NVHA $\times 10^{3}$ & NGV & $\mathrm{P} 100 \mathrm{G}$ \\
\hline $\mathrm{V}_{3} \mathrm{~N}_{0}$ & 1447 & 1104 & 3,01 & 43,02 & $1687^{1 /}$ & $2057^{1 /}$ & 4,71 & 17,14 & $1460^{1 /}$ & $14520^{1 /}$ & 4,82 & 20,57 \\
\hline $\mathrm{V}_{3}+5 \mathrm{~N}_{0}$ & 1403 & 1021 & 3,25 & 42,29 & $1723^{1 /}$ & $2053^{1 /}$ & 4,99 & 16,62 & $1367^{1 /}$ & $1496^{\frac{1 /}{}}$ & 4,28 & 21,00 \\
\hline $\mathrm{V}_{3}+10 \mathrm{~N}_{0}$ & $1232^{1 /}$ & 989 & 2,89 & 42,27 & $1484^{1 /}$ & $1808^{1 /}$ & 4,72 & 17,21 & $1234^{1 /}$ & $1331^{1 /}$ & 4,47 & 21,02 \\
\hline $\mathrm{V}_{3}+15 \mathrm{~N}_{0}$ & $1235^{1 /}$ & 988 & $2,93^{1 /}$ & 41,35 & $1463^{1 /}$ & $1820^{1 /}$ & 4,77 & 16,79 & $1153^{1 /}$ & $1184^{1 /}$ & 4,43 & 21,16 \\
\hline $\mathrm{V}_{3}+20 \mathrm{~N}_{0}$ & $1220^{\frac{1}{}}$ & 949 & 3,03 & 42,27 & $1590^{1 /}$ & $1889^{1 /}$ & 4,95 & 16,47 & $1200^{\frac{1}{}}$ & $1407^{1^{\prime}}$ & 4,23 & 20,14 \\
\hline $\mathrm{V}_{3}+25 \mathrm{~N}_{0}$ & $1240^{1 /}$ & 1073 & 2,99 & 43,13 & $1478^{1 /}$ & $1886^{1 /}$ & $4,54^{1 /}$ & 16,83 & $1226^{1 /}$ & $1483^{1 /}$ & 4,09 & 19,82 \\
\hline $\mathrm{V}_{3} \mathrm{~N}_{1}$ & 1788 & 1173 & 3,43 & 43,68 & 2156 & 2416 & 4,79 & 18,63 & 2033 & 2092 & 4,64 & 20,97 \\
\hline $\mathrm{V}_{3}+5 \mathrm{~N}_{1}$ & 1982 & 1308 & 3,47 & 43,97 & 2095 & 2311 & 4,84 & 17,79 & 1854 & 1960 & 4,53 & 20,99 \\
\hline $\mathrm{V}_{3}+10 \mathrm{~N}_{1}$ & 1799 & 1252 & 3,28 & 43,71 & 2046 & 2268 & 4,98 & 17,26 & 1970 & 2065 & 4,46 & 21,27 \\
\hline $\mathrm{V}_{3}+15 \mathrm{~N}_{1}$ & 1578 & 1030 & 3,33 & 43,28 & 2008 & 2286 & 4,64 & 18,04 & 1747 & 1807 & 4,14 & 21,28 \\
\hline $\mathrm{V}_{3}+20 \mathrm{~N}_{1}$ & 1556 & 1098 & 3,28 & 42,76 & 1888 & 2189 & 4,89 & 18,03 & 1684 & 1738 & 4,47 & 21,65 \\
\hline $\mathrm{V}_{3}+25 \mathrm{~N}_{1}$ & 1391 & 957 & 3,26 & 43,39 & 1953 & 2183 & 4,86 & 18,11 & $1352^{\frac{1}{\prime}}$ & $1539^{\frac{1}{}}$ & 4,18 & 20,89 \\
\hline Test. c/capina & $1891 \mathrm{~A}$ & $1235 \mathrm{~A}$ & $3,45 \mathrm{~A}$ & $44,13 \mathrm{~A}$ & $2216 \mathrm{~A}$ & $2452 \mathrm{~A}$ & $5,03 \mathrm{~A}$ & $17,90 \mathrm{~A}$ & $2202 \mathrm{~A}$ & $2263 \mathrm{~A}$ & $4,49 \mathrm{~A}$ & $21,56 \mathrm{~A}$ \\
\hline Test. s/capina & $1370 \mathrm{~B}$ & 1068 A & $3,05 \mathrm{~B}$ & $41,79 \mathrm{~B}$ & 1396 B & $1878 \mathrm{~B}$ & $4,26 \mathrm{~B}$ & $16,90 \mathrm{~A}$ & $1382 \mathrm{~B}$ & $1518 \mathrm{~B}$ & $4,24 \mathrm{~A}$ & $20,83 \mathrm{~A}$ \\
\hline $\mathrm{CV}(\%)$ & 19,19 & 17,91 & 9,23 & 4,40 & 14,92 & 14,22 & 7,20 & 5,40 & 19,37 & 16,05 & 4,81 & 5,08 \\
\hline
\end{tabular}

$1^{\prime}$ Diferem significativamente da testemunha com capina, pelo teste de Dunnett, a $5 \%$ de probabilidade.

${ }_{2}$ Médias seguidas pela mesma letra não diferem significativamente, pelo teste $\mathrm{F}$, a $5 \%$ de probabilidade.

$\mathrm{V}_{3}$ = Estádio de desenvolvimento dos cultivares de feijão (15 dias após emergência), quando a primeira folha trifoliolada de $50 \%$ das plantas estava totalmente aberta.

$\mathrm{N}_{0}=0 \mathrm{~kg} / \mathrm{ha} \mathrm{de} \mathrm{N}$ em cobertura.

$\mathrm{N}_{1}=30 \mathrm{~kg} / \mathrm{ha}$ de $\mathrm{N}$ distribuído em cobertura em cobertura imediatamente após cada época de capina. 
feijão quando ocorre competição entre a cultura e as plantas daninhas. Somente no 'Novo Jalo' a competição das plantas daninhas não causou redução do NVHA; entretanto, reduziu o NGV e o P100G. No 'Ouro Negro', o único componente de produção prejudicado pela competição de plantas daninhas, além da PG, foi o NVHA, enquanto no 'Ouro', foram o NVHA e o NGV.

Não se verificou influência da adubação nitrogenada em cobertura no NGV dos cultivares Ouro e Ouro Negro. Entretanto, essa adubação promoveu aumento significativo da PG, nesses cultivares. $\mathrm{O}$ nitrogênio também aumentou significativamente o P100G nos cultivares Novo Jalo e Ouro Negro e o NVHA, nos três cultivares (Tabela 2).

A adubação nitrogenada em cobertura aumentou o P100G do 'Ouro' somente no primeiro ano (Tabela 3) e o PG e NGV do 'Novo Jalo', nos dois anos (Tabela 4). Observa-se ainda que, na ausência ou presença de nitrogênio em cobertura, detectaram-se valores superiores do P100G do 'Ouro', no segundo ano (Tabela 3), e da PG e do NGV do 'Novo Jalo', no primeiro ano (Tabela 4). Esses resultados estão de acordo com Amane (1994) e Diniz et al. (1995) que obtiveram aumentos significativos na produtividade de grãos e no peso de 100 grãos, quando utilizaram $30 \mathrm{~kg}$ de N/ha em cobertura. Diniz et al. (1995) verificaram, ainda, aumento no número de vagens por planta, mas não detectaram influência do nutriente no número de grãos por vagem.

TABELA 2. Valores médios da produtividade de grãos (PG), do número de vagens por hectare (NVHA), do número de grãos por vagem (NGV) e do peso de 100 grãos (P100G) dos 'Novo Jalo', 'Ouro' e 'Ouro Negro', em cada dose de nitrogênio, no cultivo da "seca".

\begin{tabular}{|c|c|c|c|c|}
\hline $\begin{array}{c}\text { Doses de N } \\
(\mathrm{kg} / \mathrm{ha})\end{array}$ & $\begin{array}{c}\mathrm{PG} \\
(\mathrm{kg} / \mathrm{ha})\end{array}$ & NVHA & NGV & $\begin{array}{c}\text { P100G } \\
(\mathrm{g})\end{array}$ \\
\hline & \multicolumn{4}{|c|}{ 'Novo Jalo' } \\
\hline 0 & 1296 & $1021 \mathrm{~B}$ & 3,02 & $42,39 \mathrm{~B}$ \\
\hline \multirow[t]{2}{*}{30} & 1682 & $1135 \mathrm{~A}$ & 3,34 & $43,47 \mathrm{~A}$ \\
\hline & \multicolumn{4}{|c|}{ 'Ouro' } \\
\hline 0 & $1571 \mathrm{~B}$ & $1919 \mathrm{~B}$ & $4,78 \mathrm{~A}$ & 16,84 \\
\hline \multirow[t]{2}{*}{30} & $2024 \mathrm{~A}$ & $2276 \mathrm{~A}$ & $4,83 \mathrm{~A}$ & 17,98 \\
\hline & \multicolumn{4}{|c|}{ 'Ouro Negro' } \\
\hline 0 & $1273 \mathrm{~B}$ & $1392 \mathrm{~B}$ & $4,39 \mathrm{~A}$ & 20,62 B \\
\hline 30 & $1773 \mathrm{~A}$ & $1867 \mathrm{~A}$ & $4,40 \mathrm{~A}$ & $21,18 \mathrm{~A}$ \\
\hline
\end{tabular}

Em cada característica, as médias seguidas pela mesma letra não diferem significativamente, pelo teste $\mathrm{F}$, a 5\% de probabilidade.

TABELA 3. Valor médio do peso de 100 grãos (P100G) do 'Ouro', em cada dose de nitrogênio, em dois anos, no cultivo da "seca"

\begin{tabular}{lcc}
\hline Anos & \multicolumn{2}{c}{ P100G $(\mathrm{g})$} \\
\cline { 2 - 3 } & $0 \mathrm{~kg} / \mathrm{ha} \mathrm{de} \mathrm{N}$ & $30 \mathrm{~kg} / \mathrm{ha} \mathrm{de} \mathrm{N}$ \\
\hline 1994 & $15,92 \mathrm{~b}$ & $17,55 \mathrm{a}$ \\
1995 & $17,77 \mathrm{a}$ & $18,41 \mathrm{a}$ \\
\hline
\end{tabular}

As médias seguidas pela mesma letra, na linha, não diferem significativamente, pelo teste $\mathrm{F}$, a $5 \%$ de probabilidade. 
TABELA 4. Valores médios da produtividade de grãos (PG) e do número de grãos por vagem (NGV) do Novo Jalo", em cada dose de nitrogênio, em dois anos, no cultivo da "seca".

\begin{tabular}{lccccc}
\hline Anos & \multicolumn{2}{c}{ PG (kg/ha) } & \multicolumn{3}{c}{ NGV } \\
\cline { 2 - 3 } \cline { 5 - 6 } & $0 \mathrm{~kg} / \mathrm{ha} \mathrm{de} \mathrm{N}$ & $30 \mathrm{~kg} / \mathrm{ha} \mathrm{de} \mathrm{N}$ & & $0 \mathrm{~kg} / \mathrm{ha} \mathrm{de} \mathrm{N}$ & $30 \mathrm{~kg} / \mathrm{ha} \mathrm{de} \mathrm{N}$ \\
\hline 1994 & $1429 \mathrm{~b}$ & $2004 \mathrm{a}$ & & $3,13 \mathrm{~b}$ & $3,57 \mathrm{a}$ \\
1995 & $1164 \mathrm{~b}$ & $1360 \mathrm{a}$ & $2,91 \mathrm{~b}$ & $3,12 \mathrm{a}$ \\
\hline
\end{tabular}

Em cada característica, as médias seguidas pela mesma letra, na linha, não diferem significativamente, pelo teste $\mathrm{F}$, a $5 \%$ de probabilidade.

Em todos os experimentos e com a utilização do nitrogênio em cobertura, verificou-se redução linear da PG e do NVHA, quando expostos à competição com plantas daninhas, em função de diferentes atrasos na capina (Figura 1). Essa redução foi menor no 'Ouro', pois, esse cultivar é de hábito de crescimento indeterminado com ramificação ereta e hastes longas, promovendo maior cobertura do solo, o que evidencia a sua maior capacidade de competição. A redução da PG e do NVHA era previsível, pois, como mostra a Figura 2, a cobertura real do solo por plantas daninhas (CRPD) aumenta em função de diferentes atrasos na capina. Segundo Vieira (1970), na época da "seca" o efeito da competição de plantas daninhas é mais acentuado, evidentemente por causa da escassez de chuvas. Verifica-se, ainda, que a CRPD, no 'Ouro', ajustou-se a um modelo linear e no 'Novo Jalo' e 'Ouro Negro', ajustou-se a um modelo quadrático. Esses diferentes ajustes, mostram que a distribuição das plantas daninhas na área experimental foi bastante irregular nos dois anos de plantio.

A Figura 1 também mostra que, na ausência de nitrogênio em cobertura, não houve influência dos diferentes atrasos na capina sobre o NVHA, dos três cultivares. Entretanto, o 'Ouro', na ausência de nitrogênio em cobertura, apresentou redução linear da PG, em função de diferentes atrasos na capina.

Observa-se na Tabela 1 que o atraso da capina até 25 dias após a etapa de desenvolvimento $\mathrm{V}_{3}$, sem a utilização de adubação nitrogenada em cobertura, causou redução da PG e do NVHA do 'Ouro' e 'Ouro Negro' em relação à TCC, o que evidencia o efeito de competição de plantas daninhas sobre os feijoeiros. No 'Novo Jalo', não se observou diferença significativa da PG, em relação à TCC, quando se atrasou a capina até 5 dias após a etapa de desenvolvimento $V_{3}$ e não fez adubação nitrogenada em cobertura.

No 'Novo Jalo' e 'Ouro', a aplicação de nitrogênio em cobertura após diferentes épocas de capinas, inclusive na etapa $\mathrm{V}_{3}+\mathrm{N}_{1}$, promoveu recuperação das plantas de feijão e, conseqüentemente, não ocorreu redução significativa da $\mathrm{PG}$ e do NVHA, em relação à TCC. A possível explicação dessa recuperação é que esses cultivares, na presença de nitrogênio em cobertura, apresentaram menores reduções na PG quando expostos à competição com plantas daninhas, em diferentes atrasos de capina (Figura 1). Por isso, provavelmente, tiveram melhor aproveitamento do nitrogênio aplicado em cobertura, que proporcionou maior vigor às plantas de feijão, fornecendo-lhe maior capacidade de recuperação dos danos provocados por essas invasoras. Segundo Marschner (1986), o nitrogênio é fundamental para o crescimento e desenvolvimento de todas as plantas cultivadas, que o requerem em grandes quantidades, sendo constituinte obrigatório de aminoácidos e ácidos nucléicos. Participa, direta ou indiretamente, de inúmeros processos bioquímicos e faz parte da molécula de clorofila, sendo, portanto, indispensável à sua síntese. 
'Novo Jalo'
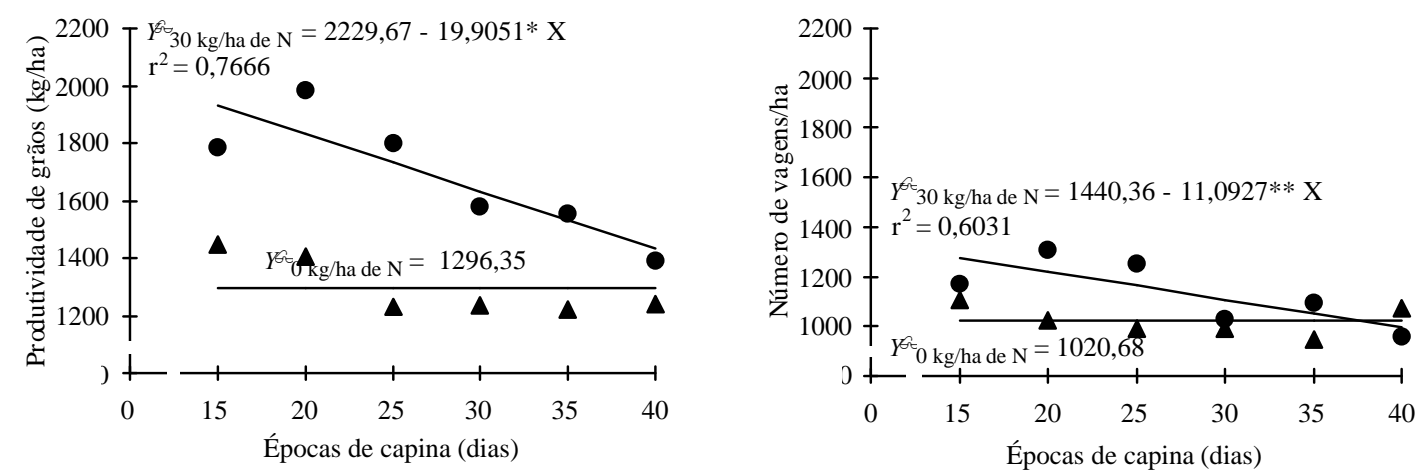

'Ouro'
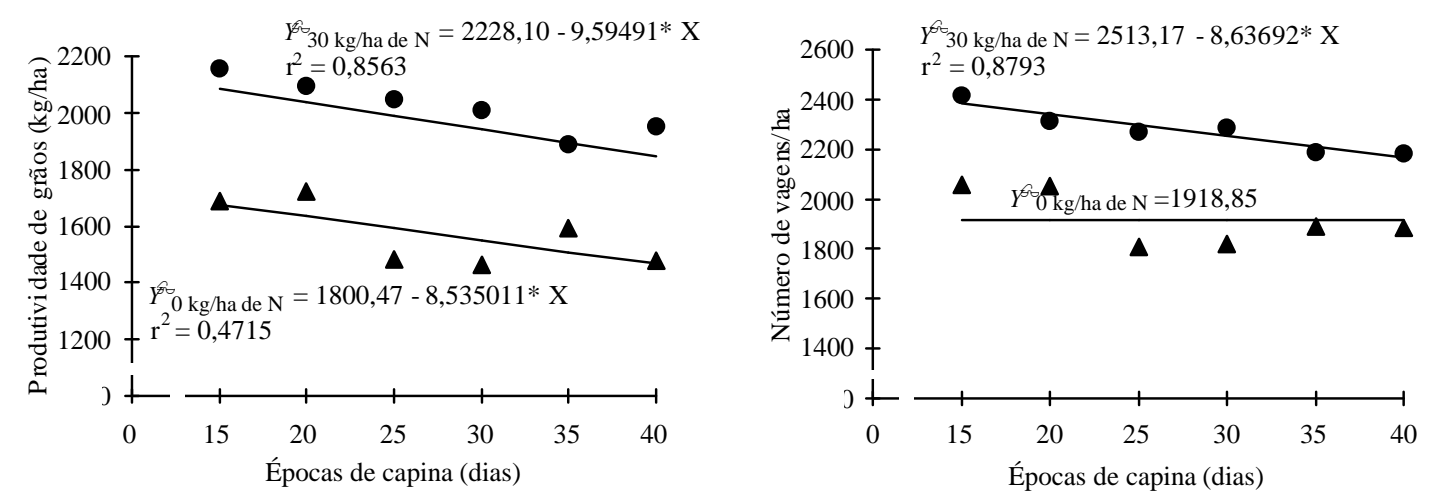

'Ouro Negro'
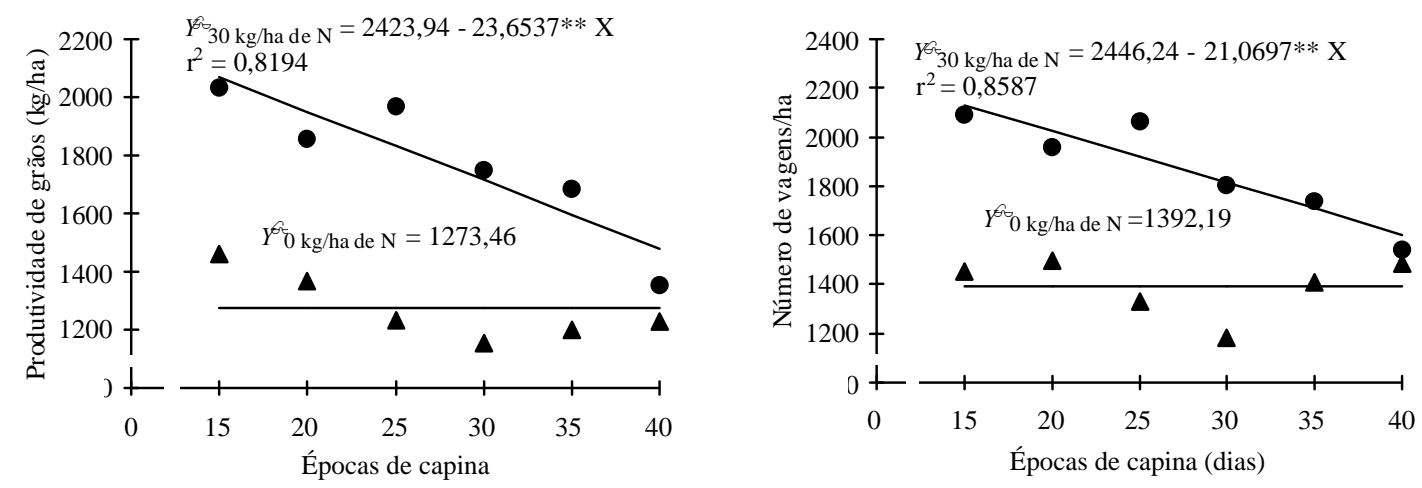

\section{$\mathrm{V}_{3}=15$ dias após emergência.}

* $\mathrm{e}^{* *}$ Significativo a 5 e a $1 \%$ de probabilidade, pelo teste " $\mathrm{t}$ ".

FIGURA 1. Estimativa da produtividade de grãos e do número de vagens/ha ( $\left.\nvdash^{\prime}\right)$ do 'Novo Jalo', 'Ouro' e 'Ouro Negro', avaliados na ausência e presença de nitrogênio, em função de diferentes épocas de capina $(\mathrm{X})$, no cultivo da "seca". 

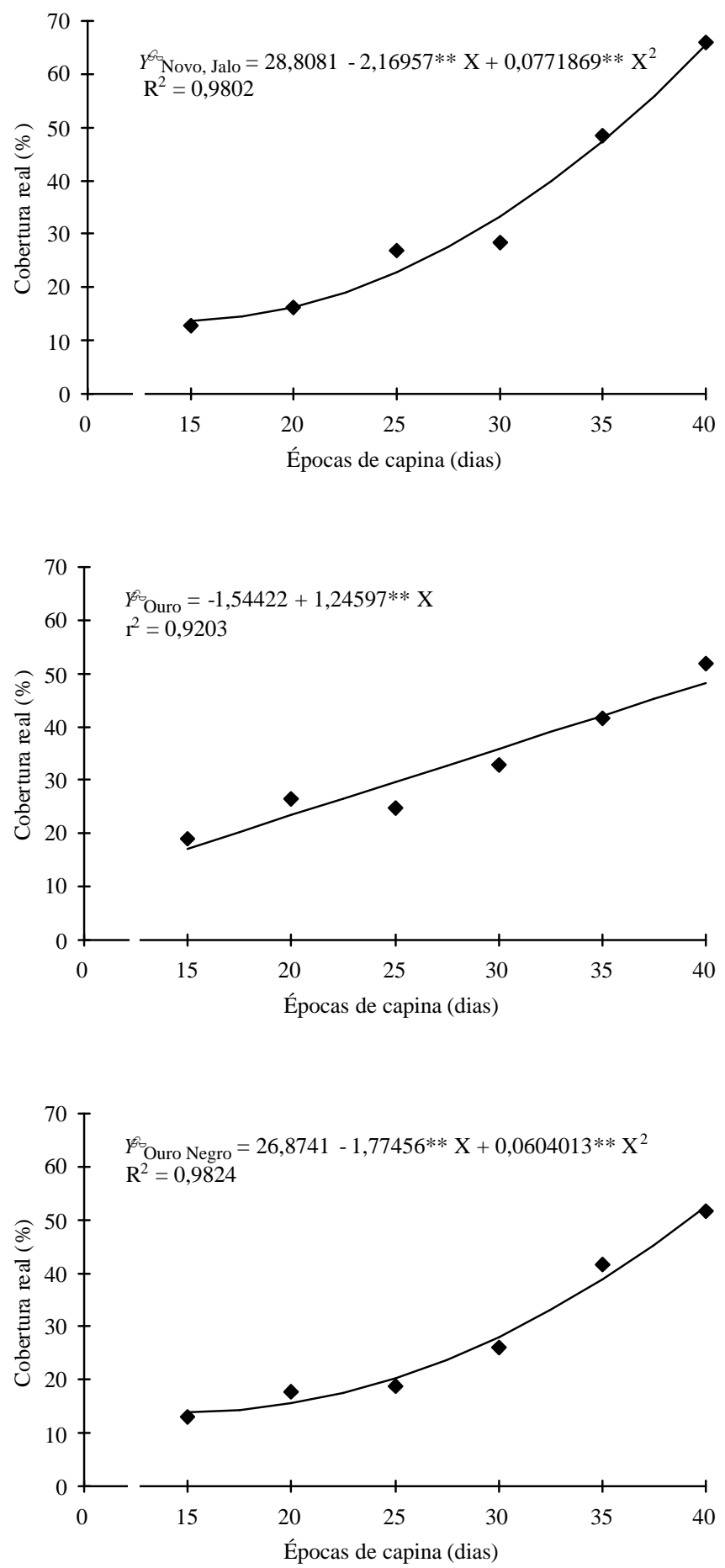

$\mathrm{V}_{3}=15$ dias após emergência.

** Significativo a $1 \%$ de probabilidade, pelo teste " $\mathrm{t}$ ".

FIGURA 2. Estimativa da cobertura real de plantas daninhas $\left(Y^{G}\right)$ no 'Novo Jalo', 'Ouro' e 'Ouro Negro', em função de diferentes épocas de capina (X), no cultivo da "seca". 
Apenas o 'Ouro Negro' apresentou redução significativa da $\mathrm{PG}$ no tratamento $\mathrm{V}_{3}+$ $25 \mathrm{~N}_{1}$, em relação à TCC. Entretanto, no 'Novo Jalo' e 'Ouro', verificou-se tendência de menor PG no tratamento $\mathrm{V}_{3}+25 \mathrm{~N}_{1}$, em relação à $\mathrm{TCC}$ (Tabela 1). Esses fatos parecem indicar que o nitrogênio aplicado imediatamente após a capina, realizada com atraso de dez dias (tratamento $\mathrm{V}_{3}+$ $25 N_{1}$ ), em relação ao período total de prevenção da interferência, que é de 30 dias para a cultura do feijão, não foi capaz de proporcionar recuperação total da capacidade produtiva dos feijoeiros.

Os estandes inicial e final não foram influenciados pelo nitrogênio ou pelas épocas de capina, motivo pelo qual seus resultados não foram apresentados no trabalho. Tal fato pode ser atribuído à aplicação cuidadosa de fertilizantes no sulco de plantio (Cardoso et al.,1978) e à infestação de plantas daninhas, que alcançou no máximo $66 \%$ de cobertura real do solo, no 'Novo Jalo', no tratamento $\mathrm{V}_{3}+25$ (Tabela 5).

TABELA 5. Valores médios da cobertura real do solo por plantas daninhas monocotiledôneas e dicotiledôneas (CRPDM e CRPDD) no 'Novo Jalo', 'Ouro' e 'Ouro Negro', em diferentes épocas de capina (EC), no cultivo da "seca"

\begin{tabular}{|c|c|c|c|c|c|c|}
\hline \multirow{2}{*}{$\begin{array}{c}\mathrm{EC} \\
\text { (dias) } \\
\end{array}$} & \multicolumn{2}{|c|}{ 'Novo Jalo' } & \multicolumn{2}{|c|}{ 'Ouro' } & \multicolumn{2}{|c|}{ 'Ouro Negro' } \\
\hline & CPDM $(\%)$ & CPDD (\%) & CPDM $(\%)$ & CPDD $(\%)$ & CPDM $(\%)$ & CPDD (\%) \\
\hline $\mathrm{V}_{3}$ & 3,19 & 9,69 & 6,38 & 12,62 & 3,41 & 9,72 \\
\hline $\mathrm{V}_{3}+5$ & 1,96 & 14,35 & 8,14 & 18,23 & 5,32 & 12,49 \\
\hline $\mathrm{V}_{3}+10$ & 4,88 & 22,00 & 5,97 & 18,72 & 2,75 & 16,00 \\
\hline$V_{3}+15$ & 4,94 & 23,50 & 8,83 & 23,98 & 6,19 & 19,94 \\
\hline $\mathrm{V}_{3}+20$ & 6,78 & 41,66 & 10,33 & 31,23 & 9,13 & 32,44 \\
\hline$V_{3}+25$ & 10,48 & 55,45 & 11,36 & 40,52 & 13,70 & 37,86 \\
\hline
\end{tabular}

Em todos os experimentos (cultivares), observaram-se diferenças significativas da massa da matéria seca da parte aérea de plantas daninhas monocotiledôneas, dicotiledôneas e total remanescentes (MSM, MSD e MST) na TSC, em relação à TCC, com exceção da MSM no 'Novo Jalo' e no ‘Ouro’, no segundo ano (Tabela 6).

Verifica-se, na Tabela 5, que em todos os cultivares e em todas as épocas de capina ocorreu predomínio de cobertura real de plantas daninhas dicotiledôneas (CRPD). Esse predomínio também foi observado por ocasião da colheita, com maior masa da matéria seca de plantas daninhas dicotiledôneas remanescentes (Tabela 6). Esses resultados estão de acordo com Alcântra \& Carvalho (1982) que observaram, no fim do período chuvoso e início do período da seca, predominância de plantas daninhas de folhas largas.

\section{LITERATURA CITADA}

ALCÂNTARA, E.N, CARVALHO, D.A. Controle de plantas daninhas no feijão. Informe Agropecuário, v.8, n.90, p.30-33, 1982.

AMANE, M.I.V. Resposta de cultivares de feijão (Phaseolus vulgaris L.) às adubações nitrogenada e molíbdica. Viçosa, MG: UFV, 1994, 70p. Dissertação (Mestrado em Fitotecnia) - Universidade Federal de Viçosa, 1994.

BANZATTO, D.A., KRONKA, S.N. Experimentação agrícola. Jaboticabal, FUNEP, 1989. 247p. 
TABELA 6. Valores médios da massa da matéria seca da parte aérea de plantas daninhas monocotiledôneas, dicotiledôneas e total remanescentes (MSM, MSD e MST) na testemunha com capina (TCC) e na testemunha sem capina (TSC) do 'Novo Jalo', 'Ouro' e 'Ouro Negro', em dois anos, no cultivo da "seca".

\begin{tabular}{|c|c|c|c|c|c|c|}
\hline \multirow[t]{2}{*}{ Anos } & \multicolumn{2}{|c|}{$\operatorname{MSM}\left(\mathrm{g} / \mathrm{m}^{2}\right)$} & \multicolumn{2}{|c|}{$\operatorname{MSD}\left(\mathrm{g} / \mathrm{m}^{2}\right)$} & \multicolumn{2}{|c|}{$\operatorname{MST}\left(\mathrm{g} / \mathrm{m}^{2}\right)$} \\
\hline & TCC & TSC & TCC & TSC & TCC & TSC \\
\hline & \multicolumn{6}{|c|}{ 'Novo Jalo' } \\
\hline 1994 & $1,05 \mathrm{~b}$ & $6,40 \mathrm{a}$ & $5,36 \mathrm{~b}$ & $47,33 \mathrm{a}$ & $6,40 \mathrm{~b}$ & $53,74 \mathrm{a}$ \\
\hline \multirow[t]{2}{*}{1995} & $6,25 \mathrm{a}$ & $6,08 \mathrm{a}$ & $46,74 \mathrm{~b}$ & $205,22 \mathrm{a}$ & $52,99 \mathrm{~b}$ & $211,13 \mathrm{a}$ \\
\hline & \multicolumn{6}{|c|}{ 'Ouro' } \\
\hline 1994 & $1,25 \mathrm{~b}$ & $6,90 \mathrm{a}$ & $3,44 \mathrm{~b}$ & $44,38 \mathrm{a}$ & $4,70 \mathrm{~b}$ & $51,28 \mathrm{a}$ \\
\hline \multirow[t]{2}{*}{1995} & $1,17 \mathrm{a}$ & $8,20 \mathrm{a}$ & $48,59 \mathrm{~b}$ & $253,03 \mathrm{a}$ & $49,76 \mathrm{~b}$ & $261,23 \mathrm{a}$ \\
\hline & \multicolumn{6}{|c|}{ 'Ouro Negro' } \\
\hline 1994 & $1,98 \mathrm{~b}$ & $9,29 \mathrm{a}$ & $3,26 \mathrm{~b}$ & $30,81 \mathrm{a}$ & $5,25 \mathrm{~b}$ & $40,10 \mathrm{a}$ \\
\hline 1995 & $4,21 \mathrm{~b}$ & $16,18 \mathrm{a}$ & $45,07 \mathrm{~b}$ & $182,72 \mathrm{a}$ & $49,28 \mathrm{~b}$ & $198,90 \mathrm{a}$ \\
\hline
\end{tabular}

Em cada característica, as médias seguidas pela mesma letra, na linha, não diferem significativamente, pelo teste $\mathrm{F}$, a $5 \%$ de probabilidade.

CALVACHE, M., REICHARDT, K., SILVA, J.C.A., PORTEZAN FILHO, O. Adubação nitrogenada no feijão sob estresse de água. In: CONGRESSO BRASILEIRO DE CIÊNCIA DO SOLO, 25, Viçosa, MG, 1995. Resumos expandidos... Viçosa, MG, SBCS/UFV, 1995. v. 3. p.649-651.

CARDOSO, A.A., FONTES, L.A.N., VIEIRA, C. Efeito de fontes e doses de adubo nitrogenado sobre a cultura do feijão (Phaseolus vulgaris L.). Rev. Ceres, v.25, n. 139, p. 292-295, 1978.

COMISSÃO DE FERTILIDADE DO SOLO DO ESTADO DE MINAS GERAIS.

Recomendações para o uso de corretivos e fertilizantes em Minas Gerais. $4^{\text {a }}$ Aproximação. Lavras, 1989. 159p.

CRUZ, C.D., REGAZZI, A.J. Modelos biométricos aplicados ao melhoramento genético. Viçosa, MG, UFV, 1994. 390p.

DINIZ, A.R., ANDRADE, M.J.B., CARVLHO, J.G., LIMA, S.F. Resposta da cultura do feijão (Phaseolus vulgaris L.) à aplicação de nitrogênio (cobertura e semeadura) e de molibdênio foliar. In: CONGRESSO BRASILEIRO DE CIÊNCIA DO SOLO, 25, Viçosa, MG, 1995. Resumos expandidos... Viçosa, MG, SBCS/UFV, 1995. v. 3, p.1125-1127.

INSTITUTO BRASILEIRO DE GEOGRAFIA E ESTATÍSTICA.

Levantamento

Sistemático da Produção Agrícola, v.7, n.5, p.1-51, 1995.

MARSCHNER, H. Mineral nutrition of higher plants. London, Academic Press, 1986. $674 p$.

NIET O, J.H., BRONDO, M.A., GONZALEZ, J.T. Critical periods of the crop growth cicle for competition from weeds. Pest Articles and News Summaries. Sectio n C, v.14, n.2, p.159-166, 1968.

PITELLI, R.A. Interferência de plantas daninhas em culturas agrícolas. Inf orm e Agropecuá rio, v.11, n.129, p.16-27, 1985. 
Efeitos de épocas de capinas e da adubação nitrogenada em cobertura sobre os componentes de produção do feijoeiro. II - Cultivo da "seca"

VIEIRA, C. Período crítico de competição entre ervas daninhas e a cultura do feijão (Phaseolus vulgaris L.). Rev. Ceres, v.17, n.94, p.354-367, 1970.
VIEIRA, C. Influência das épocas de plantio sobre as etapas de desenvolvimento do feijoeiro (Phaseolus vulgaris L.). Rev. Ceres, v.38, n.219, p.438-443, 1991. 